Research Article

\title{
Study on Safety Performance of Building Finish Layer under Thermomechanical Coupling Condition
}

\author{
Kai Yan $\left(\mathbb{D},{ }^{1}\right.$ Yansong $\mathrm{Hu},{ }^{1}$ Kaozhong Zhao, ${ }^{1}$ and Xin $\mathrm{Lin}^{2}$ \\ ${ }^{1}$ School of Civil Engineering, Shandong Jianzhu University, Jinan, China \\ ${ }^{2}$ Rise Sun Real Estate Development Co., Ltd., Chennai, India \\ Correspondence should be addressed to Kai Yan; yankai@sdjzu.edu.cn
}

Received 9 June 2021; Accepted 31 August 2021; Published 20 September 2021

Academic Editor: Francesco Colangelo

Copyright (C) 2021 Kai Yan et al. This is an open access article distributed under the Creative Commons Attribution License, which permits unrestricted use, distribution, and reproduction in any medium, provided the original work is properly cited.

\begin{abstract}
The building finish layer is a comprehensive structural system including the building exterior insulation system and building exterior finish. Combining with buildings has the advantage of reducing wall heat loss and building deformation caused by large temperature differences. Since the building finish layer is prone to cracking, hollowing, and peeling, during the application process, its safety needs to be studied and certified. This study prepares 20 groups of specimens, 15 anchor bolts in each group. The anchor bolt pull-out strength test is carried out. Anchoring damage evolution law and failure mode of anchor bolts are investigated. And the influence of anchoring methods on the pull-out bearing capacity is analyzed. In addition, ABAQUS finite element data simulation is carried out. The stress state of finish in thermomechanical coupling condition and without the effect of temperature are compared and analyzed. The influence factors of anchor bolt pull-out strength and the influence of temperature load on the long-term performance of building finish layer are obtained. The durability of the building finish layer is analyzed. The results show that the anchoring strength of the anchor bolt is positively correlated with the anchoring depth. The anchoring strength is influenced significantly by anchoring construction sequence and temperature. The stress under the coupled effect of temperature and load is greater than that of the single effect of load, and the stress distribution changes significantly. Due to thermal expansion and contraction, the anchor bolt would loosen, which is more prone to damage the building finish layer in a low temperature environment. The weight relationship of each influencing factor of the building finish layer is proposed. A systematic evaluation index system is established. The results of this study provide a basis for subsequent related research work and engineering applications.
\end{abstract}

\section{Introduction}

The building finish layer is a comprehensive structural system including the building exterior insulation system and building exterior finish. As one of the building envelope, it can enhance the beauty of the building. It also helps to reduce the heat loss $[1,2]$ and the deformation of the building caused by the temperature difference. Therefore, it can help in energy conservation and increase the service life of buildings. According to relevant statistics, more than 95\% of new buildings in China have used building finish layers.

The building finish layer is widely used in new residential buildings, and the renovation of old communities has developed into an industry. Under the influence of temperature, humidity, load, material property degradation, and service life, there will be various degrees of cracking, hollowing, peeling, and other phenomena. The building finish layer cannot fully meet the requirements of the specification [3] during use. This problem caused casualties and economic looses, which need to be solved urgently in the finish layer of the building.

There are many factors that damage the building finish layer, and the current research [4-6] is limited to the influence of individual factors on the building finish layer system $[7,8]$. Some scholars have conducted research on a specific thermal insulation material, and systematic research on the building finish layer is still blank [9-12]. For the anchoring performance of anchor bolts [13], the main focus is on fatigue failure and bearing capacity $[14,15]$. The existing codes have limitations on the safety evaluation of the 
building finish layer, which are too absolute, and the quantitative and qualitative indicators are blurred.

Based on the research status of the above building finish layer, this study carried out anchor bolt pull-out strength tests and finite element analysis results. This study prepares 20 groups of specimens, 15 anchor bolts in each group. The influence of anchoring depth, anchoring construction sequence, and temperature on anchoring strength is obtained. To verify the accuracy of the test results, compare the results of the anchor bolt pull-out strength test with the refined model analysis results. This work studies the influence of the building finish layer under the condition of temperatureload coupling. For the rigid finish layer, semirigid finish layer, and flexible finish layer, the results of temperature field analysis, no-temperature stress field analysis, and temperature-load coupling analysis are carried out, respectively, to obtain the influence of temperature load on the finish layer. Regarding the long-term performance of the building finish layer, combined with related literature $[16,17]$, the effects of heat-humidity cycles, heat-cold cycles and heat-rain cycles on the building finish layer are summarized. Finally, in view of the problems existing in the engineering application of the classification boundaries in the existing specifications for building finish layers, this study proposes a fuzzy evaluation method. The evaluation method adopts the method of engineering experience survey; through the method of frequency statistics, the weight value and membership degree of each material are obtained. After that, the calculation formulas of related quantitative indicators and qualitative indicators are put forward, and an evaluation method for the building finish layer is established.

\section{Anchor Bolt Pull-Out Strength Test and Simulation Analysis}

\subsection{Anchor Bolt Pull-Out Strength Test}

2.1.1. Test Design. The test parameters are anchorage depth, anchorage construction sequence, and temperature change. The aerated concrete blocks used in the test are the same batch of materials. The section size is $600 \mathrm{~mm} \times 200$ $\mathrm{mm} \times 250 \mathrm{~mm}$ as shown in Figure 1. The plastic anchor bolt uses a percussive disc anchor, the disc diameter is $50 \mathrm{~mm}$, the expansion sleeve diameter is $10 \mathrm{~mm}$, and the expansion sleeve has a total length of $162 \mathrm{~mm}$, as shown in Figure 2. The anchoring depth is set to four types: $50 \mathrm{~mm}, 60 \mathrm{~mm}, 70 \mathrm{~mm}$, and $80 \mathrm{~mm}$. There are two ways of construction sequence: normal construction sequence (inserting the plastic expansion sleeve into the drilled hole and then driving the steel nail into the plastic expansion sleeve) and simultaneous anchoring (driven plastic expansion sleeve and steel nails into the block together). Temperature changes mainly considered the temperature difference between construction and use. This study prepares 20 groups of specimens, 15 anchor bolts in each group.

The spot layout of the test piece is shown in Figure 3. In order to avoid the difference of aerated concrete block materials from affecting the test results, different anchorage depths are arranged on the same block in this test.

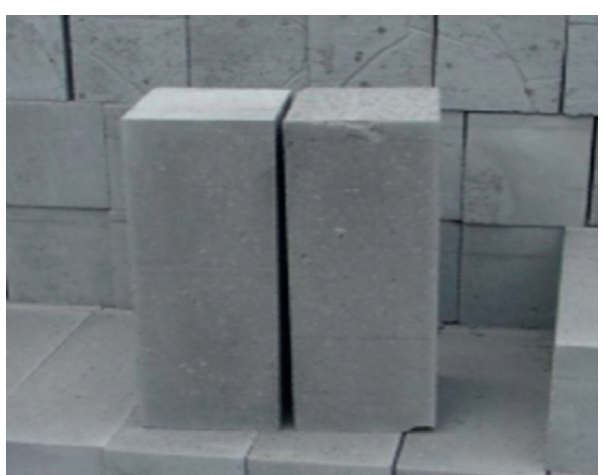

FIGURE 1: Aerated concrete block.

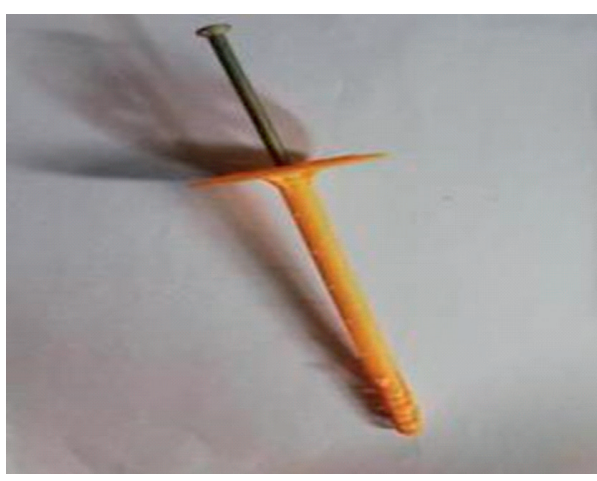

Figure 2: Plastic anchor bolt.

In the main view, considering that the puller is constrained by distance requirements during operation, it is impossible to implant anchor bolts at 10 measuring points at the same time. Thus, the test is divided into two batches: the location of the first batch of measuring points is $1,2,5$, 6,9 , and 10 , and the second batch is $3,4,7$, and 8 . In the side view, the measuring point are implanted with 5 anchor bolts at a time. The anchor bolt layout after anchoring is shown in Figure 4.

2.1.2. Test Setup. The loading instrument for this test is the HC-MD60 high-precision rivet puller as shown in Figure 5. The force loading mode is adopted during the test. A unidirectional tensile load is applied to the anchor casing, as shown in Figure 6. When loading, the puller and the anchor bolt are in the same straight line. When the load displayed by the puller remains unchanged, the anchor bolt is pulled out.

2.1.3. Result and Discussion. During the test, there are three results: the anchor bolt is pulled out as a whole. The plastic expansion, the casing is pulled off, and the metal anchor bolt is not pulled out. The plastic expansion sleeve is pulled off, and the metal anchor bolt is pulled out. The typical test results of anchor bolts are shown in Figure 7.

The construction sequence of all anchor bolts in this group is normal. The relevant drawing test data are given in Table 1. The results show that the pull-out strength of the 


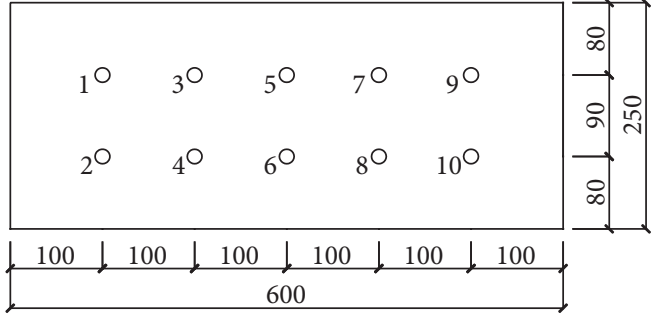

(a)

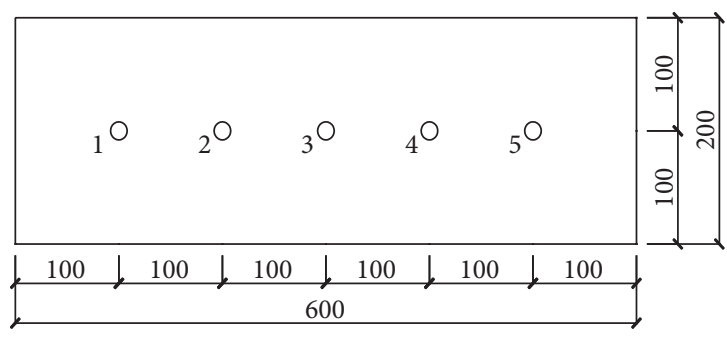

(b)

FIGURE 3: Layout drawing of block measuring points (unit: mm). (a) Main view. (b) Side view.

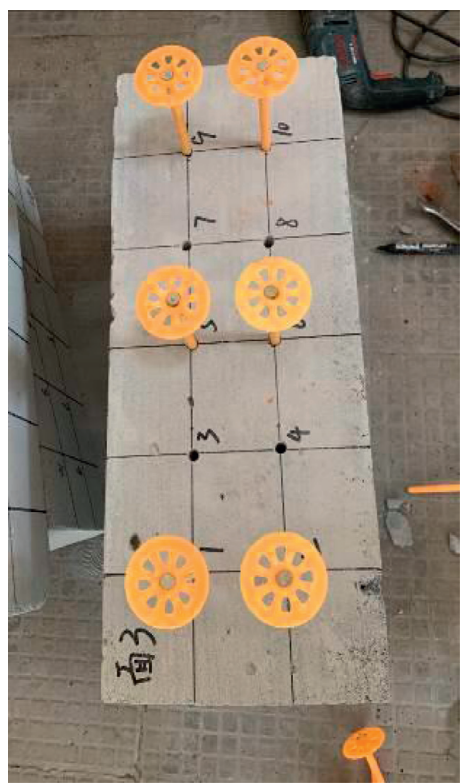

(a)

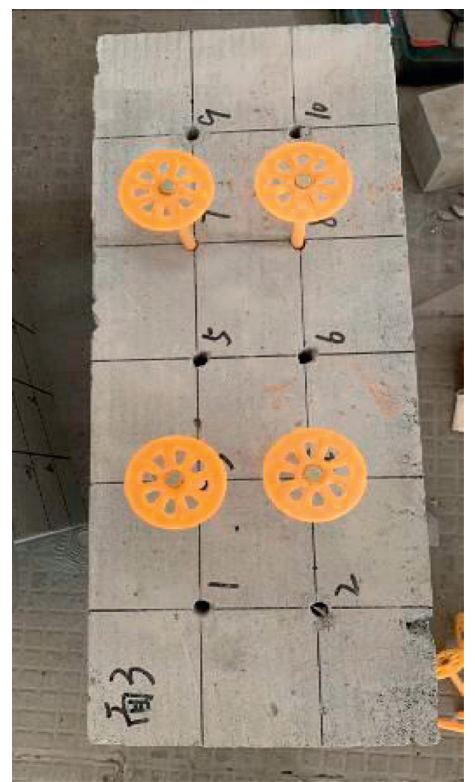

(b)

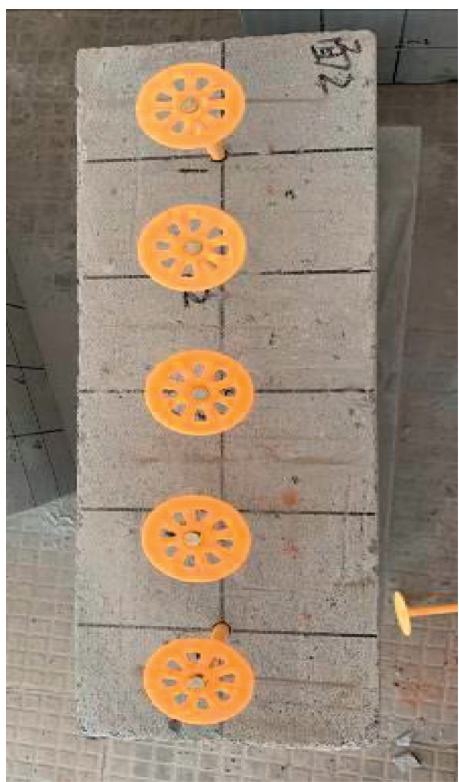

(c)

Figure 4: Anchor bolt layout. (a) The first batch in the main view. (b) The second batch in the main view. (c) Side view.

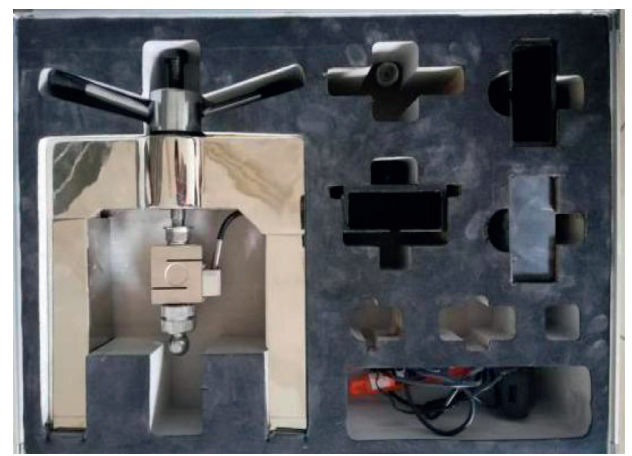

FIGURE 5: HC-MD60 high-precision rivet puller.

anchor bolt is positively correlated with the anchoring depth. For every $10 \mathrm{~mm}$ increase in anchorage depth, the anchoring force of the anchor bolt will increase by about $21.4 \%$.

In order to study the influence of the anchoring construction sequence on the anchoring strength of the anchor bolt, the normal construction sequence and simultaneous anchoring are carried out, and the results are given in
Table 2. It can be found that the anchoring strength of simultaneous anchoring is reduced by about $70 \%$ compared with the normal construction sequence.

Considering the influence of temperature changes on the anchoring strength of anchor bolts, the anchor bolt pull-out strength tests under different ambient temperatures are designed. The anchor bolts are constructed at ambient temperatures of $20^{\circ} \mathrm{C}$ and $38^{\circ} \mathrm{C}$, respectively, and then, the anchor bolt pull-out strength tests are carried out in the season when the ambient temperature is $20^{\circ} \mathrm{C}, 38^{\circ} \mathrm{C}$, and $-5^{\circ} \mathrm{C}$. The results are given in Table 3 . The greater the temperature difference between the driving of the rivet and the pull-out strength test, the more obvious the reduction in the anchoring strength of the anchor bolts. This is because the thermal expansion coefficients of the aerated concrete block and the anchor bolt are different, resulting in temperature deformation, the extrusion force between the anchor bolt and the block is reduced, and the pull-out resistance is also reduced. The anchor bolt is prone to loosening under long-term action, which affects the stability and safety of the finish layer. 


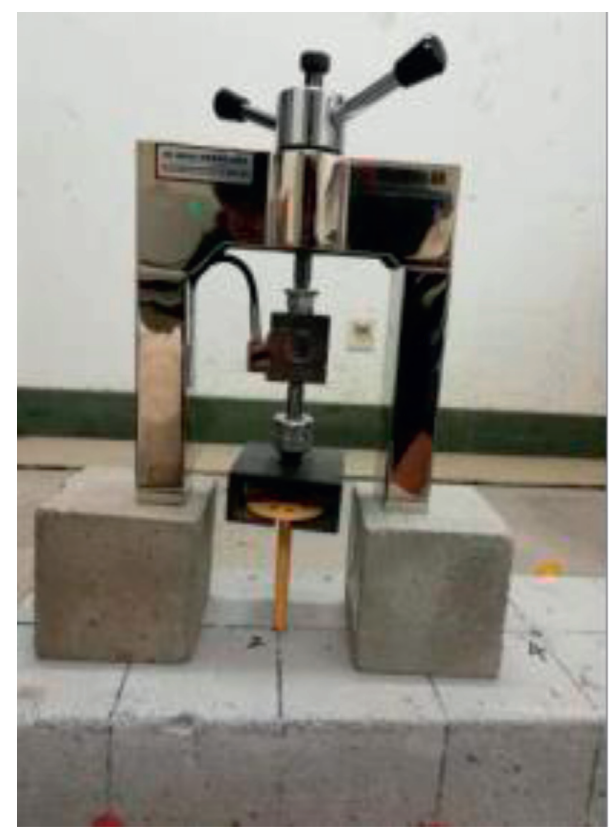

Figure 6: Test loading diagram.

2.2. Anchor Bolt Drawing Simulation. Modeling and analyzing anchor bolts of different depths. Both anchor bolts and blocks use C3D8R entities to establish unit models, and the stress field element uses a C3D20 R: 20 node quadratic reduction integral hexahedral element. When building the model, the diameter of the anchor bolt is $10 \mathrm{~mm}$, and the diameter of the reserved hole of the block is $10 \mathrm{~mm}$. The variable of the anchor pull simulation test is the anchoring depth, which is $60 \mathrm{~mm}, 70 \mathrm{~mm}$, and $80 \mathrm{~mm}$, respectively. The boundary conditions around the model are completely fixed. The material properties of anchor bolts and blocks are given in Table 4. The constitutive relationship is shown in Figure 8. The schematic diagram of anchor bolt anchoring is shown in Figure 9, and the model mesh is shown in Figure 10.

The simulation results show that the influence range of a single anchor bolt can reach $70 \mathrm{~mm}$, which is 7 times the diameter of the anchor bolt. Its maximum principal stress can reach $0.54 \mathrm{MPa}$ and the maximum bond stress is $0.32 \mathrm{MPa}$. The distribution of Mises principal stress inside the aerated concrete block before and after anchor bolt drawing is shown in Figure 11, and 12 shows the distribution of the bond stress.

The comparison of pull-out strength test data and simulated data under different anchoring depths is shown in Figure 13. The comparison shows that the simulation data iare $4.82 \%$ larger than the test data, and the simulation analysis agrees with the test data. Therefore, it can provide data support for the subsequent modeling and analysis of the finish layer.

\section{Building Finish Layer Simulation and Durability Analysis}

\subsection{Refined Finite Element Model of Safety Performance of the Finish Layer}

3.1.1. Model Establishment. According to the different softness and hardness of the internal insulation material of the finish layer, it can be divided into three types of structural forms: rigid finish layer, semirigid finish layer, and flexible finish layer. This article analyzes the modeling of three types of the finish layer. In order to simplify the modeling, it is divided into seven parts: masonry wall, interface layer, insulation layer, bonding layer, facing brick, casing, and metal nails. The rigid finish layer has no external wall insulation anchor bolts, and the material is a vitrified microbead insulation mortar. The semirigid finish layer adopts external wall insulation anchor bolts, and the material is mainly semirigid materials such as polystyrene board. The flexible material also uses anchor bolts, but the materials are mainly flexible materials such as thermal insulation rock wool. The simplified model structure diagram is shown in Figure 14.

3.1.2. Model Parameter Setting and Material Property Definition. The model size of the rigid finish layer is set to $1 \times 1 \mathrm{~m}^{2}$, and the model size of the semirigid finish layer and flexible finish layer is $0.3 \times 0.3 \mathrm{~m}^{2}$. The material properties under heating-cooling cycles[18] are adopted. In addition, relevant specifications such as JGJ144-2017 technical specification for external wall thermal insulation engineering [19], JGT 366-2012 anchor bolt for external wall thermal insulation [20], national standard, and GB 11968-2006 autoclaved aerated concrete block [21] are taken as the basis for selection and comparison of relevant material parameters. The material parameters used are given in Table 5 .

3.1.3. Mesh Division and Boundary Conditions. The threedimensional solid element model is adopted in this modeling. The element type of temperature field is DC3D20: 20 node secondary heat transfer hexahedron, and the element type of stress field is C3D20 R: 20 node secondary reduced integral hexahedron. The mesh generation of the model is shown in Figure 15. Among them, the semirigid finish layer and the flexible finish layer both use insulation anchor bolts, so the same model is constructed.

\subsection{Calculation Results and Analysis of the Finish Layer}

3.2.1. Analysis of Temperature Field Results. The temperature field of rigid veneer, semirigid veneer, and flexible veneer was simulated. The simulation analysis has obtained the heating curve of each layer of the building finish layer in $2.5 \mathrm{~h}$. It is found that there is a difference in the ultimate temperature of each layer for materials, and the temperature difference in the insulation layer is large. The temperature load of the rigid surface layer is $50^{\circ} \mathrm{C}$, the maximum temperature difference before and after the insulation layer is $23.6^{\circ} \mathrm{C}$, and the temperature difference between the inside and outside of the surface layer reaches $29.5^{\circ} \mathrm{C}$. At $-20^{\circ} \mathrm{C}$, the temperature difference between before and after is $6.6^{\circ} \mathrm{C}$ and $39.2^{\circ} \mathrm{C}$, respectively. The semirigid finish layer anchor bolt has an obvious thermal bridge effect, which causes the temperature difference of the insulation layer to reach $11.5^{\circ} \mathrm{C}$. For semirigid materials at $50^{\circ} \mathrm{C}$, the gradient of the limit temperature of different materials is shown in Figure 16. 


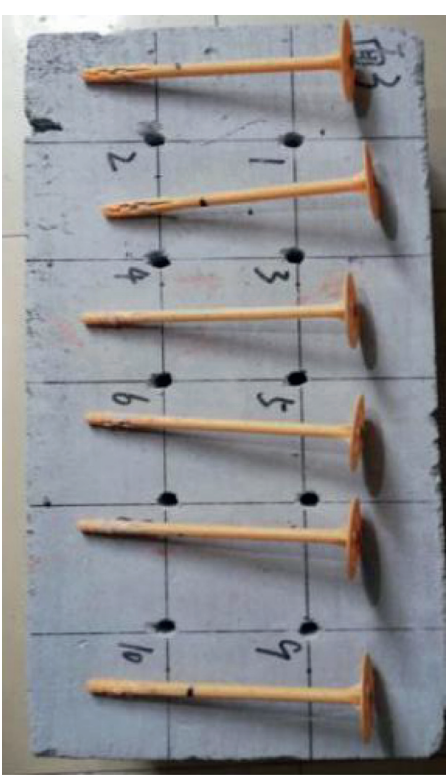

(a)

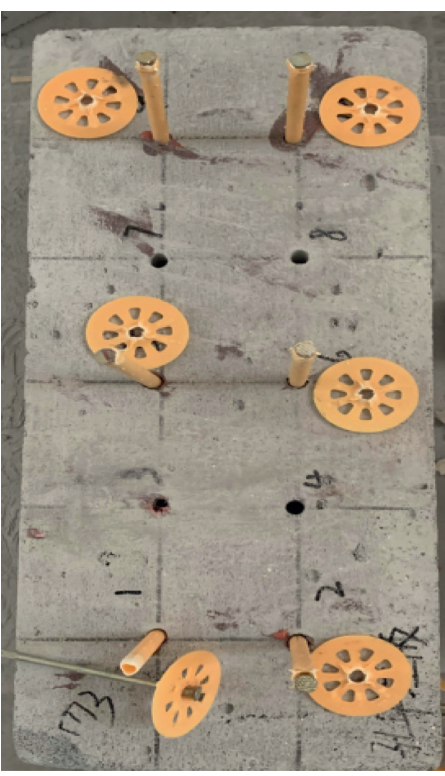

(b)

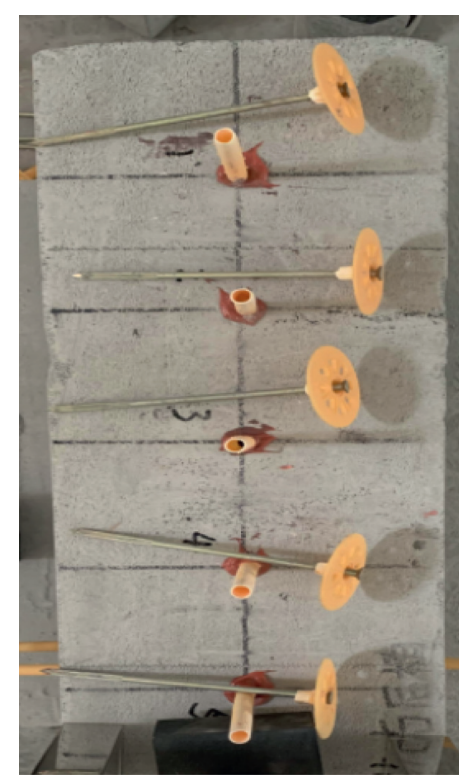

(c)

Figure 7: Anchor bolt pull-out strength test results.

Table 1: Pull-out strength test data of different anchorage depths.

\begin{tabular}{lcccc}
\hline $\begin{array}{l}\text { Anchor bolt } \\
\text { diameter }(\mathrm{mm})\end{array}$ & Drill diameter $(\mathrm{mm})$ & Anchorage depth $(\mathrm{mm})$ & Average pull-out strength $(\mathrm{kN})$ & Standard deviation \\
& & 50 & 0.319 & 0.072 \\
10 & 10 & 60 & 0.385 & 0.068 \\
& & 70 & 0.472 & 0.073 \\
\hline
\end{tabular}

TABle 2: Pull-out test strength data of different anchoring sequences.

\begin{tabular}{lccccc}
\hline $\begin{array}{l}\text { Anchor bolt diameter } \\
(\mathrm{mm})\end{array}$ & $\begin{array}{c}\text { Drill diameter } \\
(\mathrm{mm})\end{array}$ & $\begin{array}{c}\text { Anchorage depth } \\
(\mathrm{mm})\end{array}$ & $\begin{array}{c}\text { Construction } \\
\text { sequence }\end{array}$ & $\begin{array}{c}\text { Average pull-out strength } \\
(\mathrm{kN})\end{array}$ & $\begin{array}{c}\text { Standard deviation } \\
\text { Normal }\end{array}$ \\
\hline & 8 & Simultaneous & 0.986 & 0.067 \\
anchoring & 0.114 & 0.074 \\
& & Normal & 0.385 & 0.069 \\
& 10 & 60 & $\begin{array}{c}\text { Simultaneous } \\
\text { anchoring }\end{array}$ & 0.099 & 0.072 \\
\hline
\end{tabular}

TABLe 3: Pull-out test strength data of different temperatures.

\begin{tabular}{lccccc}
\hline $\begin{array}{l}\text { Drill diameter } \\
(\mathrm{mm})\end{array}$ & $\begin{array}{c}\text { Anchor bolt diameter } \\
(\mathrm{mm})\end{array}$ & $\begin{array}{c}\text { Anchorage } \\
\text { depth }(\mathrm{mm})\end{array}$ & $\begin{array}{c}\text { Construction temperature } \\
\left({ }^{\circ} \mathrm{C}\right)\end{array}$ & $\begin{array}{c}\text { Test temperature } \\
\left({ }^{\circ} \mathrm{C}\right)\end{array}$ & $\begin{array}{c}\text { Average pull-out strength } \\
(\mathrm{kN})\end{array}$ \\
\hline & & & 20 & 20 & 0.385 \\
10 & \multirow{2}{*}{10} & 60 & 38 & 38 & 0.383 \\
& & & 38 & -5 & 0.386 \\
\end{tabular}

TABLE 4: Material properties.

\begin{tabular}{lccccc}
\hline Material & Size $(\mathrm{mm})$ & Elastic modulus $(\mathrm{MPa})$ & Poisson's ratio & Yield strength $(\mathrm{MPa})$ & Ultimate strength $(\mathrm{MPa})$ \\
\hline Anchor bolt & $d=10$ & 165000 & 0.3 & 316 & 475 \\
Block & $h=240$ & 2000 & 0.2 & - & - \\
\hline
\end{tabular}




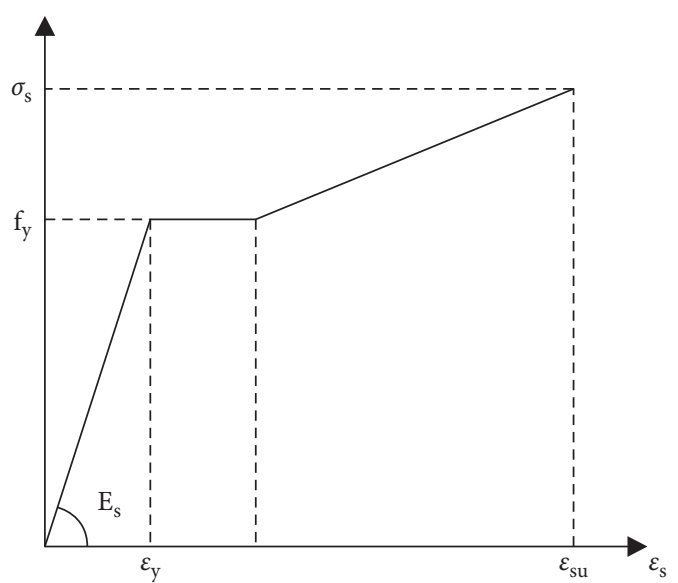

FIGURE 8: Sress-strain curve.

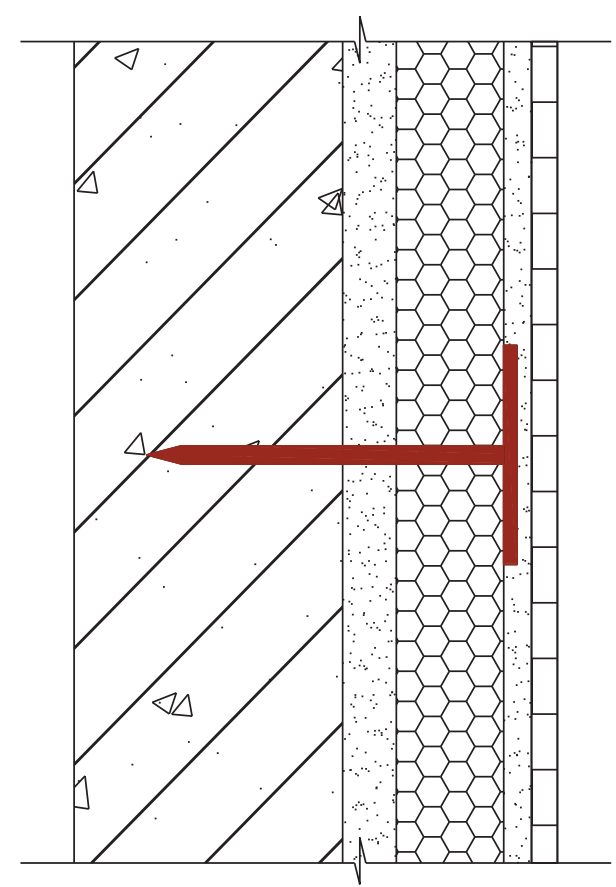

Figure 9: Anchor bolt anchoring diagram.

The flexible material is similar to the semirigid material, and the anchor bolt also has a thermal bridge effect. This makes the temperature difference between the inside and outside of the insulation layer reach $13.4^{\circ} \mathrm{C}$, and the insulation effect is better than that of the semirigid finish layer; the difference is about $3^{\circ} \mathrm{C}$. The temperature field distribution of some materials is shown in Figures 17 and 18.

The results show that the building finish layer can reduce the heat exchange between the wall and the external environment, which is beneficial to reduce the influence of the external hot and cold environment on the indoor temperature. The external wall thermal insulation material has a significant thermal insulation effect, which is conducive to maintaining the comfort of the indoor environment. At the same time, the temperature change of the building is reduced, which is conducive to its durability.

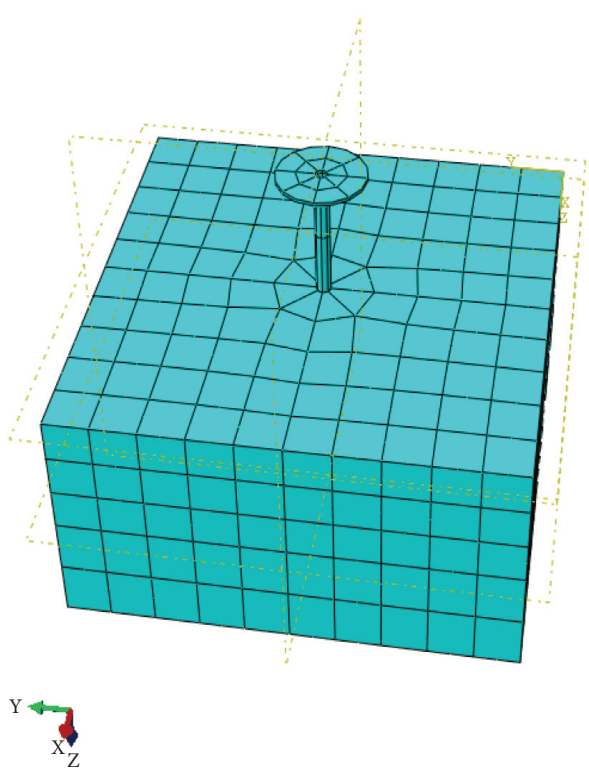

Figure 10: Anchor bolt drawing model.

3.2.2. Analysis of Stress Field Results. Temperature and load will affect the finish layer of the building and cause it to produce stress and deformation. This article studies and discusses its durability. The three types of the finish layer were analyzed in the nontemperature stress field and coupled with the temperature load. The influence of the temperature load on the building finish layer is obtained.

This article carried out the following simulation: under the action of $2000 \mathrm{~Pa}$ surface load and gravity load, the Mises principal stress and normal bonding stress were compared and analyzed under three conditions of no temperature, $50^{\circ} \mathrm{C}$, and $-20^{\circ} \mathrm{C}$. The following results are obtained through the comparative analysis under three temperature conditions: for no-temperature load, the surface load is $2000 \mathrm{~Pa}$, and the maximum surface stress is $0.04 \mathrm{MPa}$. But under $50^{\circ} \mathrm{C}$ and $-20^{\circ} \mathrm{C}$ temperature load, its maximum stress reached $2.8 \mathrm{MPa}$ and $10.3 \mathrm{MPa}$, respectively. The results show that the temperature load has a significant effect on the stress changes of each layer of materials. The stress under the coupled temperature load is higher than the stress under the separate load. The simulation results show that the stress situation in low temperature environment is significantly higher than that in high temperature environment. In winter, the building finish layer is more prone to damage, which is consistent with the realization of simulation results. This verifies the correctness of the simulation results. Figure 19 shows the principal stress distribution of some materials of the finish layer under different working conditions.

The principal stress curve changes of some materials are shown in Figure 20. The results show that the temperature load will increase the Mises principal stress of each layer of material, more obvious in low temperature environment. The materials of all layers are in the same direction except for the face brick. Facing bricks appear under the stress concentration phenomenon in low temperature environment, which will destroy the stability of the building finish layer. 


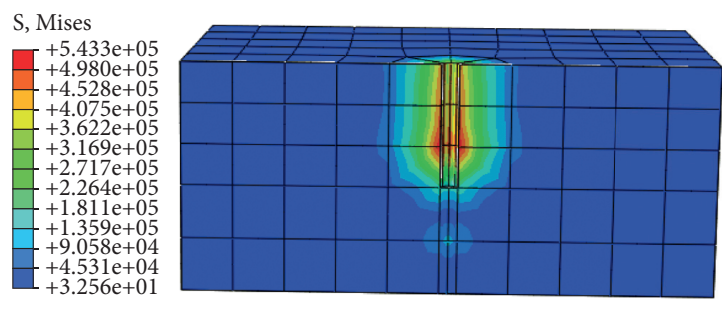

(a)

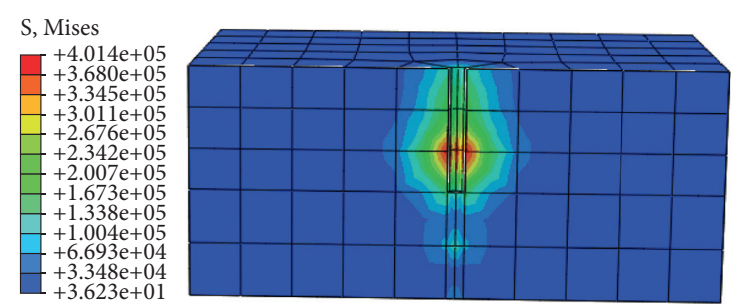

(b)

Figure 11: Mises principal stress (unit: MPa). (a) Before. (b) After.

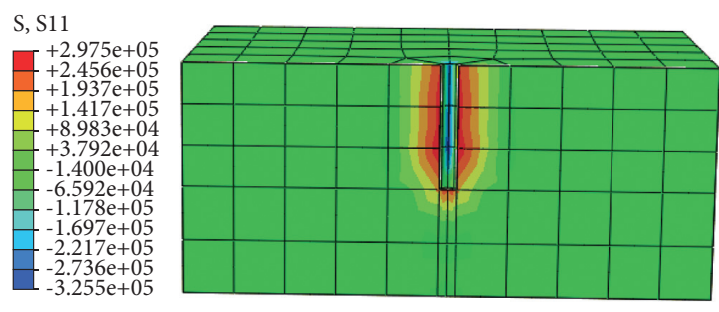

(a)

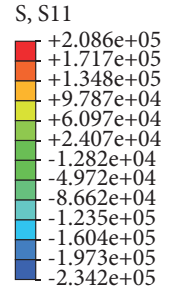

$.973 \mathrm{e}+05$

FIgURe 12: Bond stress (unit: MPa). (a) Before. (b) After.

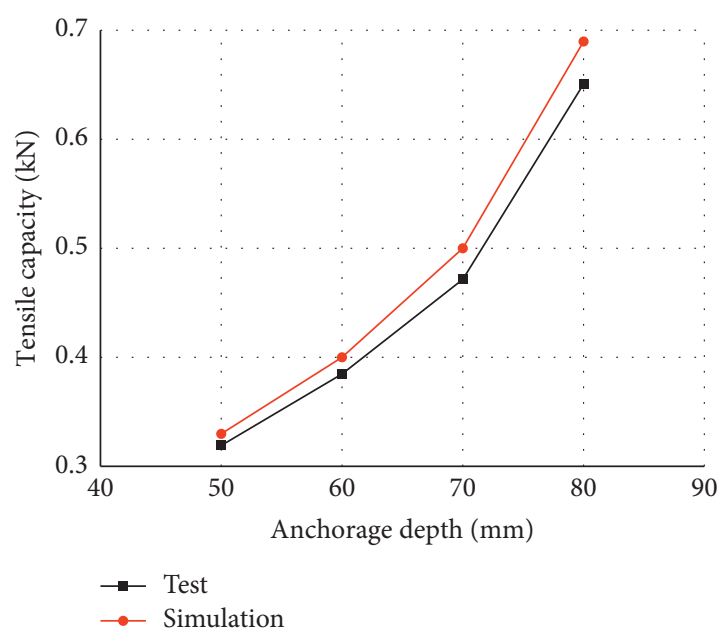

FIGURE 13: Data comparison chart.

Figure 21 shows the cloud diagram of the bond stress distribution. The bonding strength between the materials of each layer determines the stability of the building finish layer. The stress of the building finish layer material will be greatly reduced before and after the insulation layer. It is obviously affected by gravity load. This is consistent with the phenomenon of engineering damage. At the boundary conditions, there are triple effects of boundary conditions, load, and temperature. The stress change caused by temperature is more obvious.

Figure 22 shows the bond stress curve of each layer of the semirigid building finish layer at different temperatures. The stress distribution is consistent under three load conditions, and the temperature load has little effect on the bond stress. There are constraints at the boundary conditions. Temperature load will cause the direction of bond stress to change. At the boundary of the principle, the bonding stresses of the facing brick, the bonding layer, the interface layer, and the masonry wall tend to be consistent. The insulation layer has a thermal bridge effect at the anchor bolt; this makes the magnitude and direction of the bond stress at the anchor bolt greatly affected by the temperature load.

3.3. Durability Analysis of the Finish Layer. At present, some related research studies [22] have been conducted on factors such as humidity and durability. Sun [23] carried out a study on the thermal and moisture coupling of the flexible finish layer. Based on the performance of flexible materials, they established a coupled heat-moisture migration model for the flexible finish layer and established relevant evaluation indicators and methods. The result shows that the tensile bond strength of the finish layer will decrease under the effect of heat-moisture coupling. The intensity reduction is related to the duration of action, serious with time.

Liu [24] carried out comparative experiments between humidity-controlling materials and the ordinary mortar at $25^{\circ} \mathrm{C}$ and $60 \%-85 \%$ relative humidity and concluded that the moisture absorption capacity of the humidity-conditioning mortar is 6 times that of ordinary mortar. At the same time, it is highly sensitive to temperature, and as the temperature rises, the humidity control effect is significant. Through the test results, a new system combining the external wall insulation structure system and the internal plastering and humidity-controlling mortar is proposed. It has the effect of heat preservation and humidity control at the same time.

Xiang [25] studied the surface mortar under the cycle of heat-rain and carried out 20 times, 40 times, 60 times, and 80 heat-rain cycle tests respectively, also 2 times and 5 times the heat-cold cycle test. Tests have obtained various mechanical strengths (flexural strength, compressive strength, and bond 


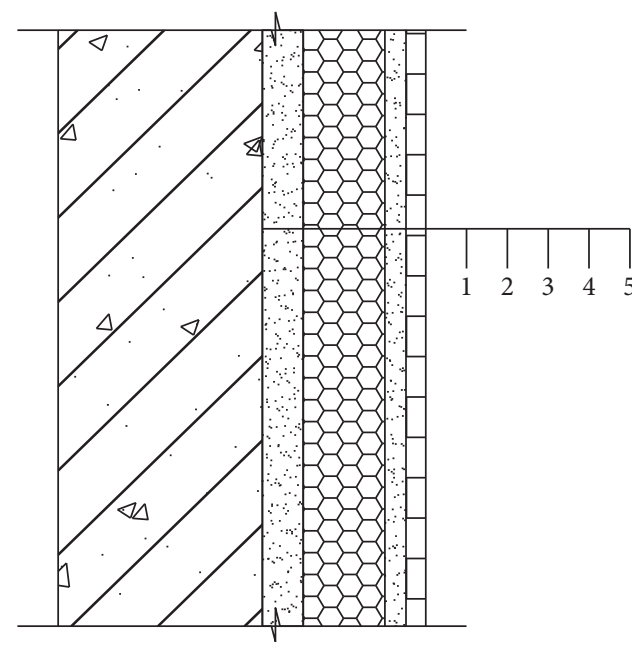

(a)

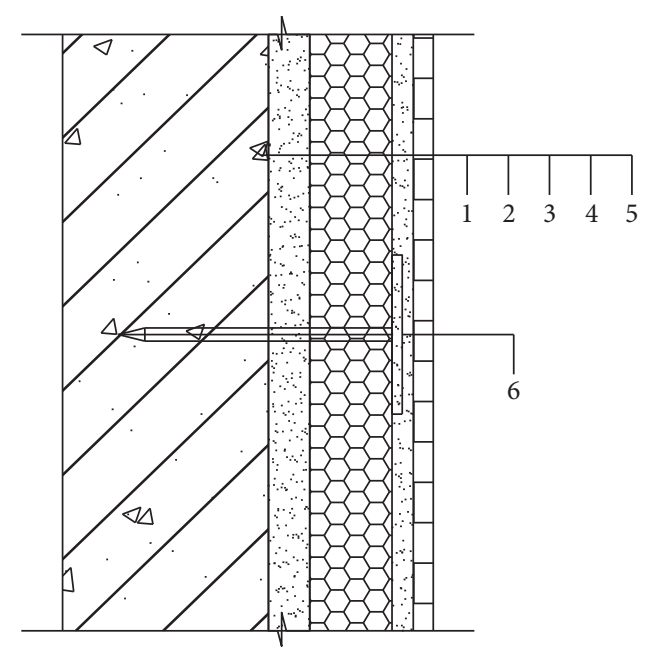

(b)

FiguRE 14: Finish layer structure diagram (1, masonry wall; 2, interface layer; 3, insulation layer; 4, adhesive layer; 5, face brick; 6, anchor bolt). (a) Rigid finish layer. (b) Semirigid and flexible finish layer.

TABLE 5: Material parameter table.

\begin{tabular}{|c|c|c|c|c|c|c|c|}
\hline Material science & $\begin{array}{l}\text { Thickness } \\
(\mathrm{mm})\end{array}$ & $\begin{array}{l}\text { Density } \\
\left(\mathrm{kg} / \mathrm{m}^{3}\right)\end{array}$ & $\begin{array}{c}\text { Thermal } \\
\text { conductivity } \\
(\mathrm{W} / \mathrm{m} \cdot \mathrm{K})\end{array}$ & $\begin{array}{c}\text { Expansion } \\
\text { coefficient }\left(10^{-6} / \mathrm{K}\right)\end{array}$ & $\begin{array}{c}\text { Elastic } \\
\text { modulus (MPa) }\end{array}$ & $\begin{array}{l}\text { Poisson's } \\
\text { ratio }\end{array}$ & $\begin{array}{c}\text { Specific } \\
\text { heat }(\mathrm{J} /(\mathrm{kg} \cdot \mathrm{K}))\end{array}$ \\
\hline $\begin{array}{l}\text { Aerated concrete } \\
\text { block }\end{array}$ & 240 & 600 & 0.24 & 8 & 2000 & 0.2 & 920 \\
\hline Interface mortar & 3 & 1600 & 0.93 & 12 & 4900 & 0.28 & 1050 \\
\hline $\begin{array}{l}\text { Thermal insulation } \\
\text { mortar }\end{array}$ & 50 & 400 & 0.07 & 8 & 1 & 0.15 & 1070 \\
\hline $\begin{array}{l}\text { Crack-resistant } \\
\text { mortar }\end{array}$ & 5 & 1800 & 0.87 & 12 & 9700 & 0.28 & 1050 \\
\hline Bonding mortar & 5 & 1600 & 0.93 & 12 & 4900 & 0.28 & 1050 \\
\hline Polystyrene board & 60 & 30 & 0.03 & 8.5 & 50 & 0.2 & 1200 \\
\hline $\begin{array}{l}\text { Thermal insulation } \\
\text { rock wool }\end{array}$ & 60 & 173 & 0.042 & 8.5 & 100 & 0.2 & 1020 \\
\hline Ceramic tile & 6 & 2250 & 1.1 & 5 & 20000 & 0.25 & 1050 \\
\hline Nylon sleeve & - & 1160 & 0.24 & 60 & 2830 & 0.4 & 1670 \\
\hline Steel nail & - & 7930 & 16.2 & 16.4 & 19500 & 0.29 & 510 \\
\hline
\end{tabular}

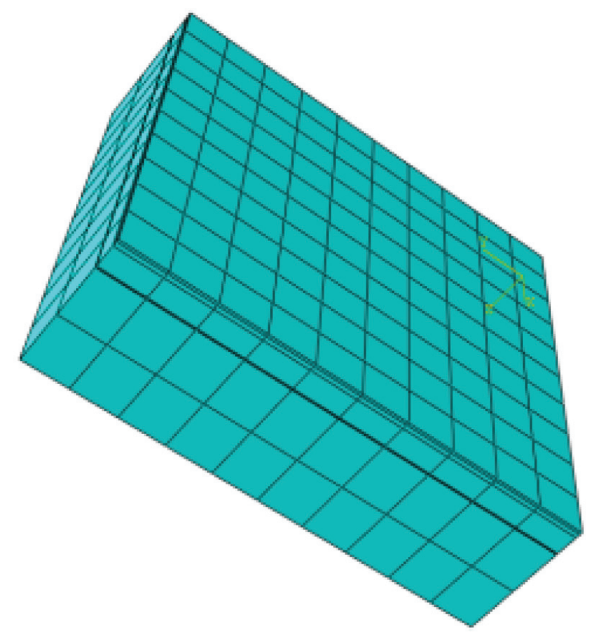

(a)

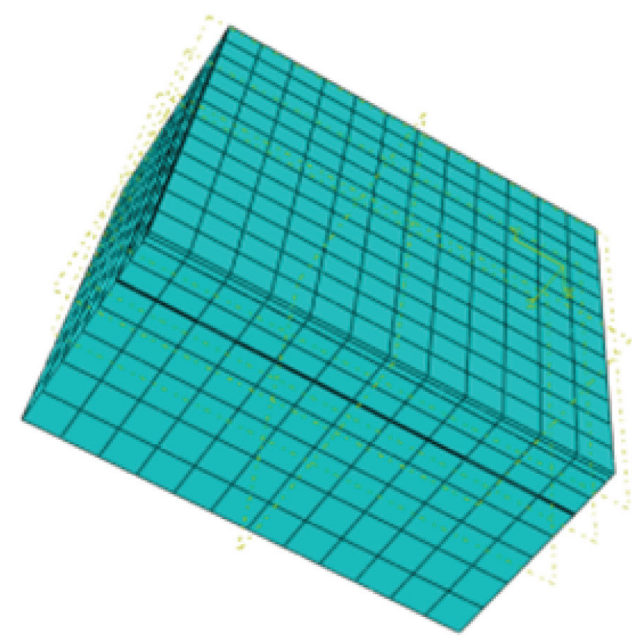

(b)

Figure 15: Model mesh generation. (a) Rigid finish layer. (b) Semirigid finish layer and flexible finish layer. 


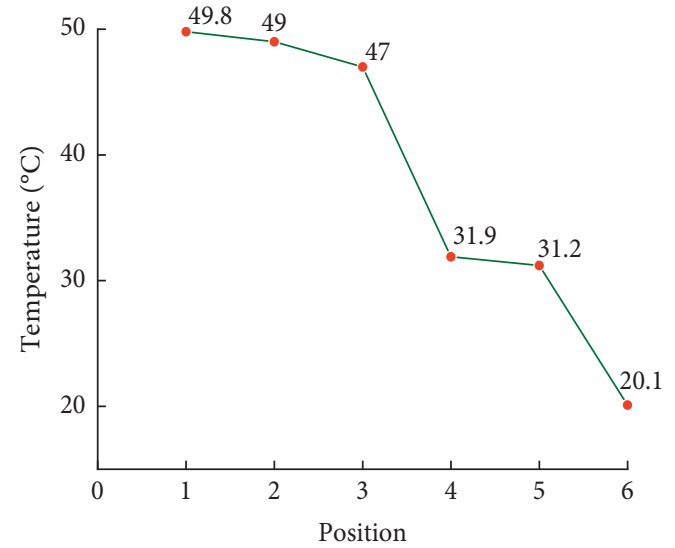

(a)

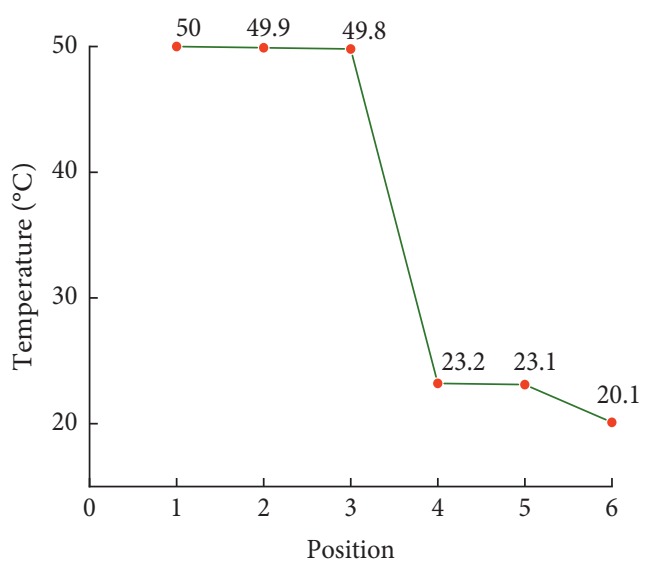

(b)

Figure 16: Temperature gradient change of the semirigid finish layer. (a) Near anchor bolt. (b) Away from the anchor bolt.
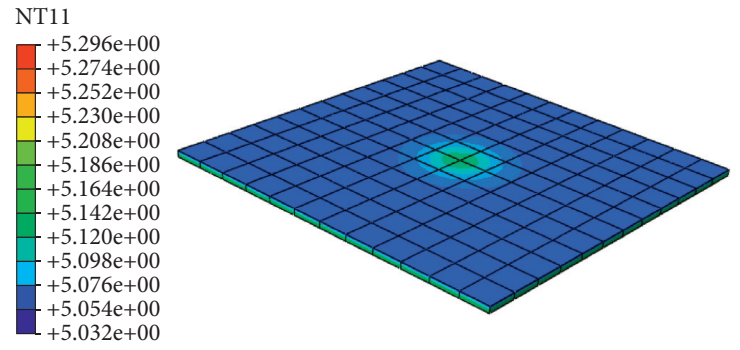

(a)

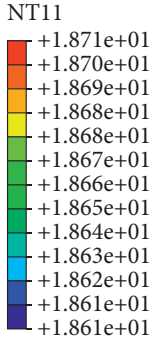

$1.861 \mathrm{e}+01$

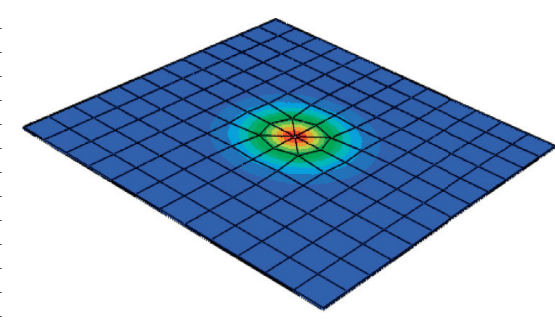

(b)

Figure 17: $-20^{\circ} \mathrm{C}$ temperature field of the semirigid finish layer (unit: ${ }^{\circ} \mathrm{C}$ ). (a) Bonding layer. (b) Interface layer.
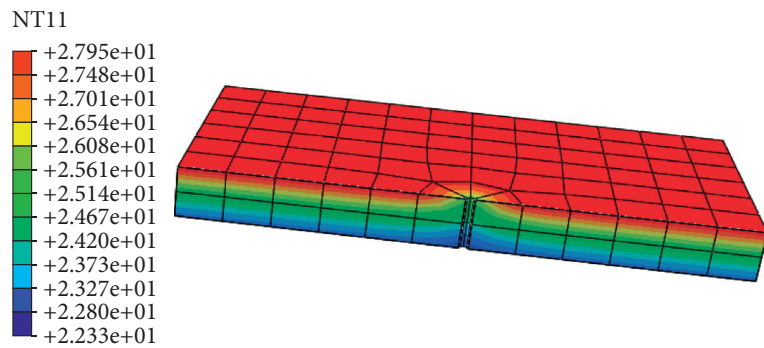

(a)
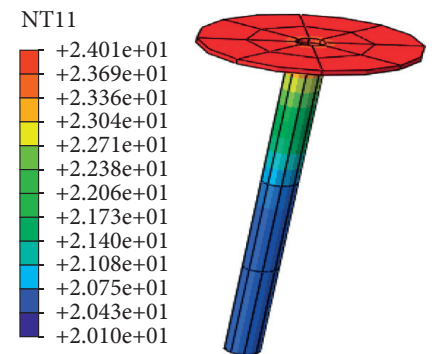

(b)

FIGURE 18: $50^{\circ} \mathrm{C}$ temperature field of the semirigid finish layer (unit: ${ }^{\circ} \mathrm{C}$ ). (a) Insulation layer. (b) Bushing.

strength). Analyze the failure mechanism by comparing the magnitude of stress in each case. Part of the test results is given in Table 6 . The bond strength test of the polymerbonded mortar is given in Table 7. In Tables 6 and 7, H-R is the heat-rain cycle, and D is the curing age. For example, $28 \mathrm{~d}+20 \mathrm{H}-\mathrm{R}$ means that the blocks undergo 20 heat-rain cycles tests after 28 days of standard curing.

The test results show that weather resistance has a great influence on the building finish layer. The flexural strength, compressive strength, and bonding strength of the polymer mortar surface are reduced.

Huo et al. [26] studied the durability of the thermal insulation mortar finish layer and modified polystyrene board finish layer through experiments. The heat-cold cycle and hotrain cycle tests were carried out on the specimens and gained its bond strength. The curve change is shown in Figure 23.

The test results show that the heat-rain cycle has a greater impact on the finish layer. With the increase of the number of tests, the plastic deformation of the building finish layer increases. The deformation of the polystyrene board is greater than that of the vitrified bead insulation mortar, and heat-cold cycles cause greater strength attenuation than heat-humidity cycles.

Due to the influence of temperature, humidity, and load, the long-term performance of building finish layers cannot meet the requirements of the specification. The temperature 


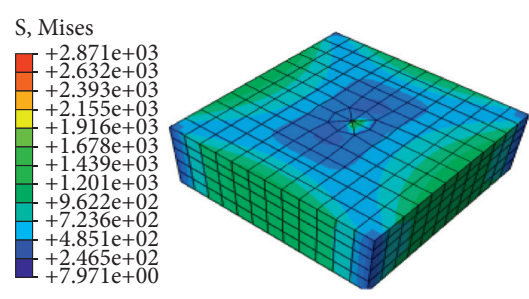

(a)

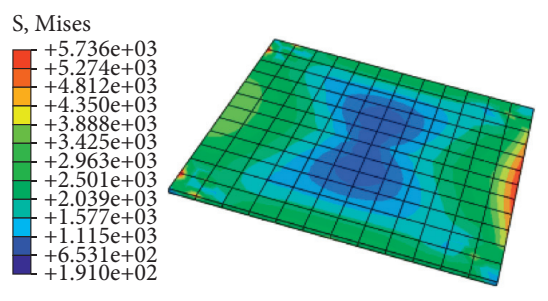

(d)

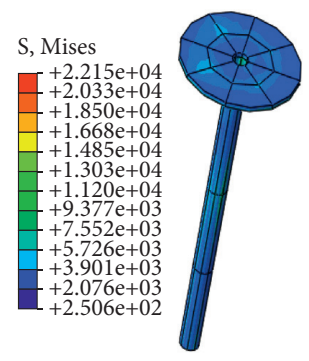

(g)
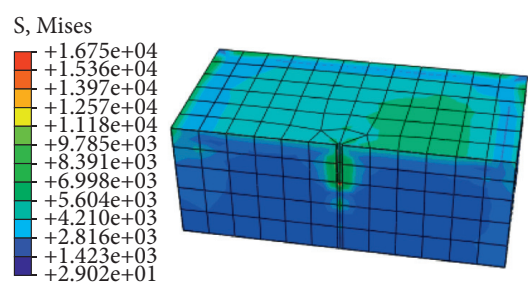

(b)

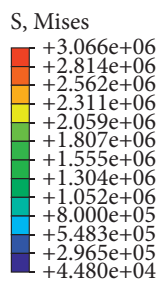

$4.480 \mathrm{e}+04$

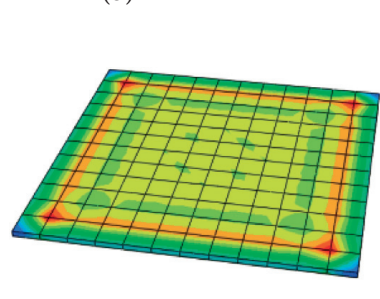

(e)

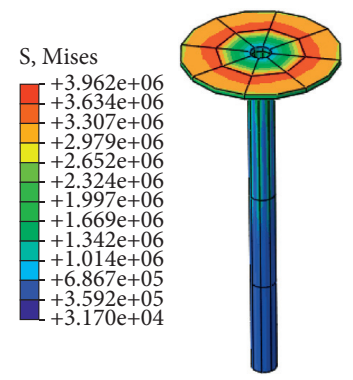

(h)

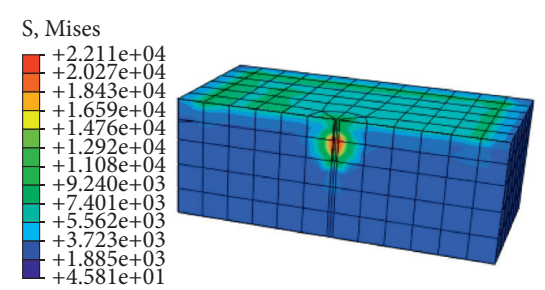

(c)

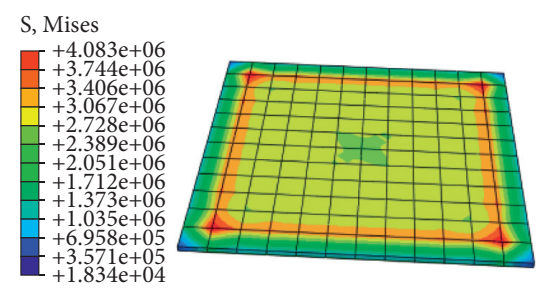

(f)

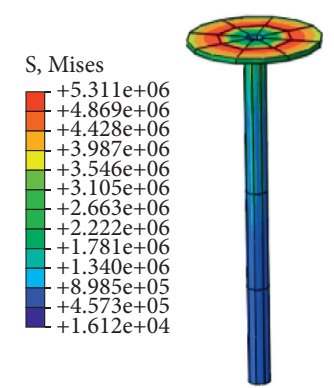

(i)

Figure 19: Principal stress distribution of the semirigid finish layer (unit: MPa). (a) Masonry wall (without temperature). (b) Masonry wall $\left(50^{\circ} \mathrm{C}\right)$. (c) Masonry wall $\left(-20^{\circ} \mathrm{C}\right)$. (d) Bonding layer (without temperature). (e) Bonding layer $\left(50^{\circ} \mathrm{C}\right)$. (f) Bonding layer $\left(-20^{\circ} \mathrm{C}\right)$. (g) Bushing (without temperature). (h) Bushing $\left(50^{\circ} \mathrm{C}\right)$. (i) Bushing $\left(-20^{\circ} \mathrm{C}\right)$.

change causes cracks in the material, thereby reducing the anchoring force of the anchor bolt, and ultimately affects the long-term performance of the building finish layer. As the number of heat and humidity cycles increases, the plastic deformation of the material becomes larger, and the bonding strength between the materials decreases. The reason is that the heat-humidity cycle causes the material to expand or contract, resulting in varying degrees of deformation. This leads to the destruction of the long-term performance of the material. And the heat-cold cycle is more harmful than the heat-humid cycle. Due to weather resistance, it is impossible to accurately analyze the plastic deformation of the building finish layer; this has resulted in an insufficient weather resistance analysis of the building finish layer, still in the preliminary exploration stage.

\section{Finish Layer Evaluation System}

4.1. Evaluation Index System. The existing comprehensive safety assessment method for the finish layer is essentially an analytic hierarchy process, which mainly includes classification of grades and weight determination. With reference to relevant specifications, an evaluation index system has been established for the building finish layer, from appearance and structure, material performance, and bearing capacity. The appearance and structure are obtained through on-site inspection. Material performance indicators are obtained through material testing. The bearing capacity index is obtained through the bearing capacity detection test, including two aspects of the bearing capacity test and review. The relevant test indicators are given in Tables 8-10.

4.2. Fuzzy Evaluation Method. There are some problems in the practical engineering application, such as absoluteness of classification boundaries, uncertainty of qualitative indicators, and complexity of influencing factors. Combined with relevant specifications [27-29], this study proposes a systematic fuzzy evaluation method for the building finish layer. The building finish layers are divided into four fuzzy grades: from good to severe, it can be divided into I, II, III, and IV, as given in Table 11.

4.3. Determination of Weight. This article uses a questionnaire to survey relevant personnel on engineering experience. Through the frequency statistics method, the six weights of thermal insulation panels, structural adhesives, anchor bolts, facing bricks, material properties, and bearing capacity are obtained. The weight relationship of the underlying indicators is determined. According to the questionnaire survey results of the weight $\left(u_{i} \longrightarrow w_{i j}, i\right.$, 

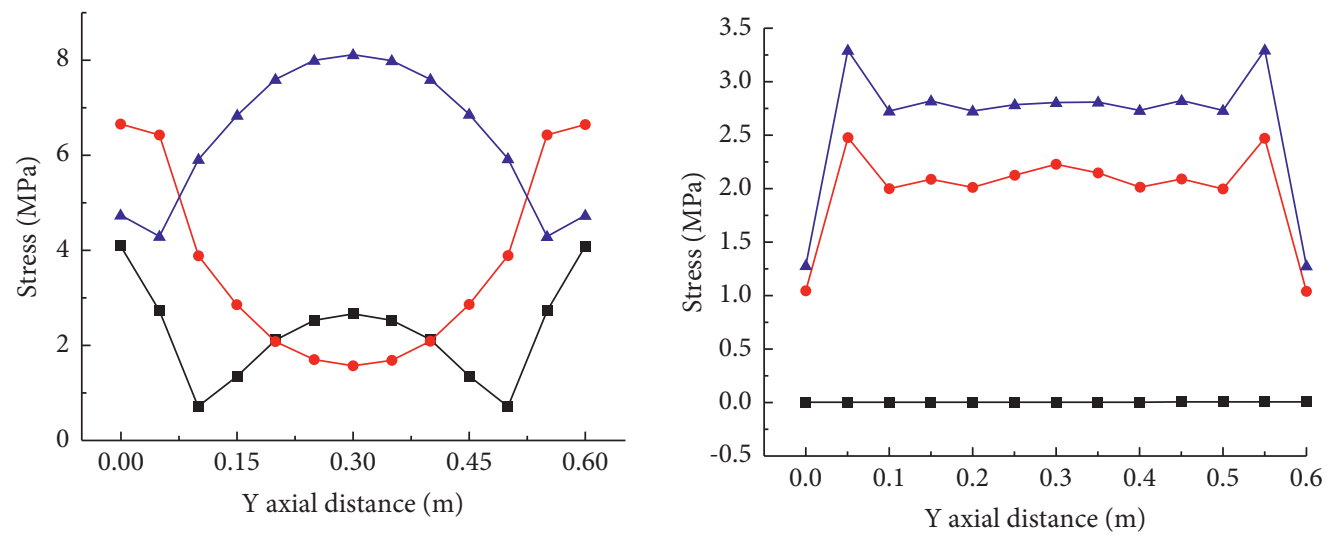

$$
\begin{aligned}
& \rightarrow \text { No Temperature } \\
& \rightarrow 50^{\circ} \mathrm{C} \\
& \leftarrow-20^{\circ} \mathrm{C}
\end{aligned}
$$

$\rightarrow$ No Temperature

$\rightarrow 50^{\circ} \mathrm{C}$

$\rightarrow-20^{\circ} \mathrm{C}$

(a)

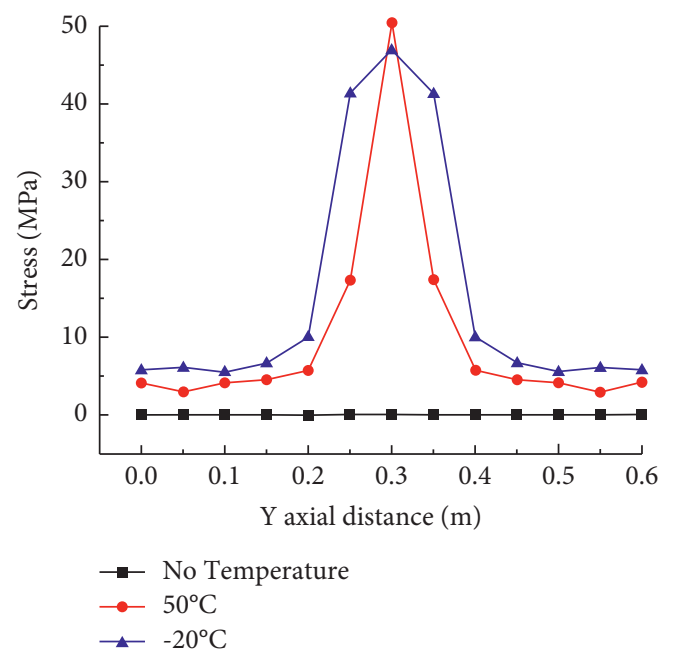

(c)

(b)

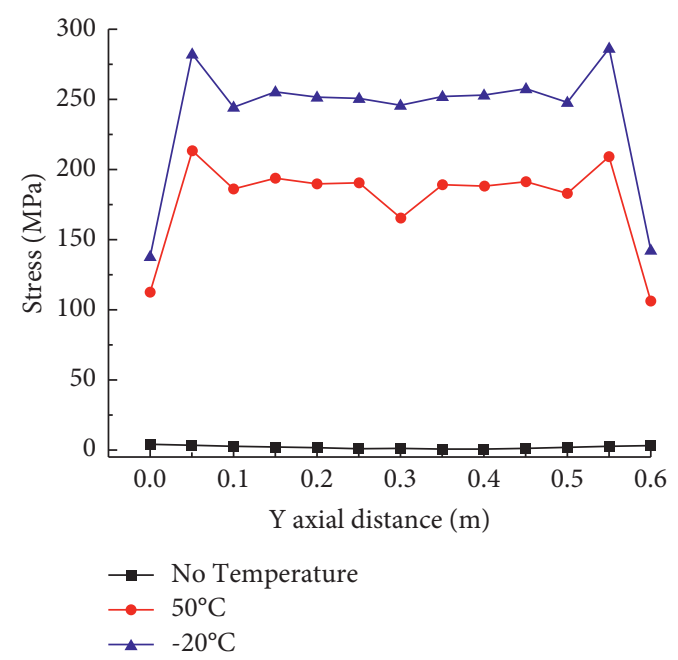

(d)

FIGURE 20: Comparison of Mises principal stress of the semirigid finish layer. (a) Face brick. (b) Bonding layer. (c) Insulation layer. (d) Interface layer.
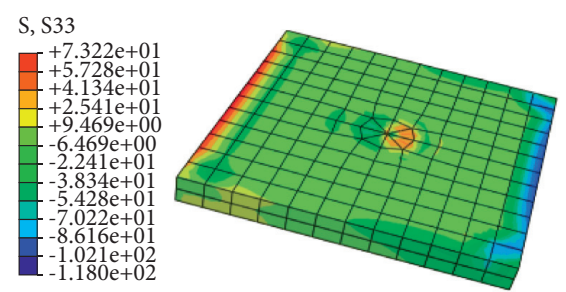

(a)
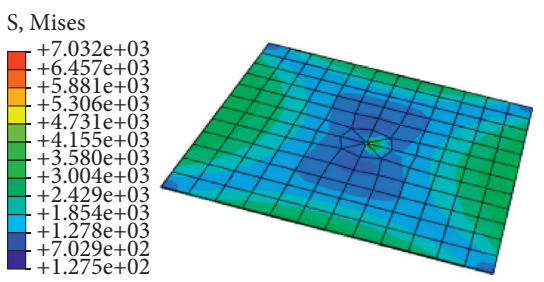

(d)

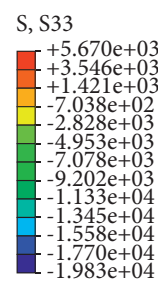

$1.983 \mathrm{e}+04$

S, Mises

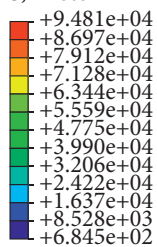

$-8.528 \mathrm{e}+03$
$+6.845 \mathrm{e}+02$

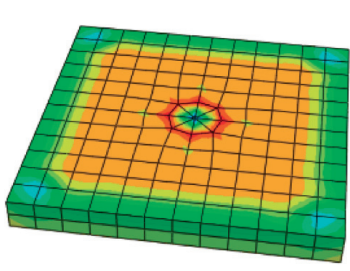

(b)

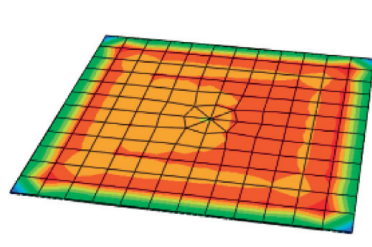

(e)

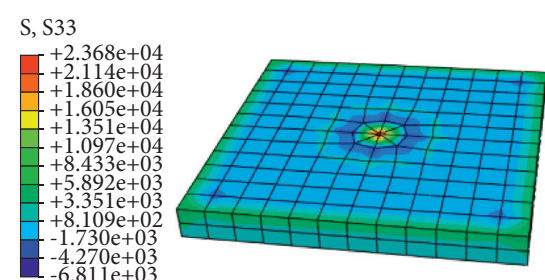

(c)
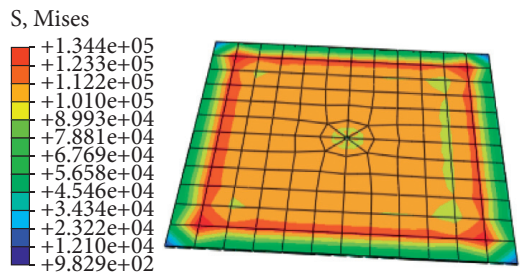

(f)

FIGURE 21: Normal bond stress distribution of the semirigid finish layer (unit: MPa). (a) Insulation layer (without temperature). (b) Insulation layer $\left(50^{\circ} \mathrm{C}\right)$. (c) Insulation layer $\left(-20^{\circ} \mathrm{C}\right)$. (d) Interface layer (without temperature). (e) Interface layer $\left(50^{\circ} \mathrm{C}\right)$. (f) Interface layer $\left(-20^{\circ} \mathrm{C}\right)$. 

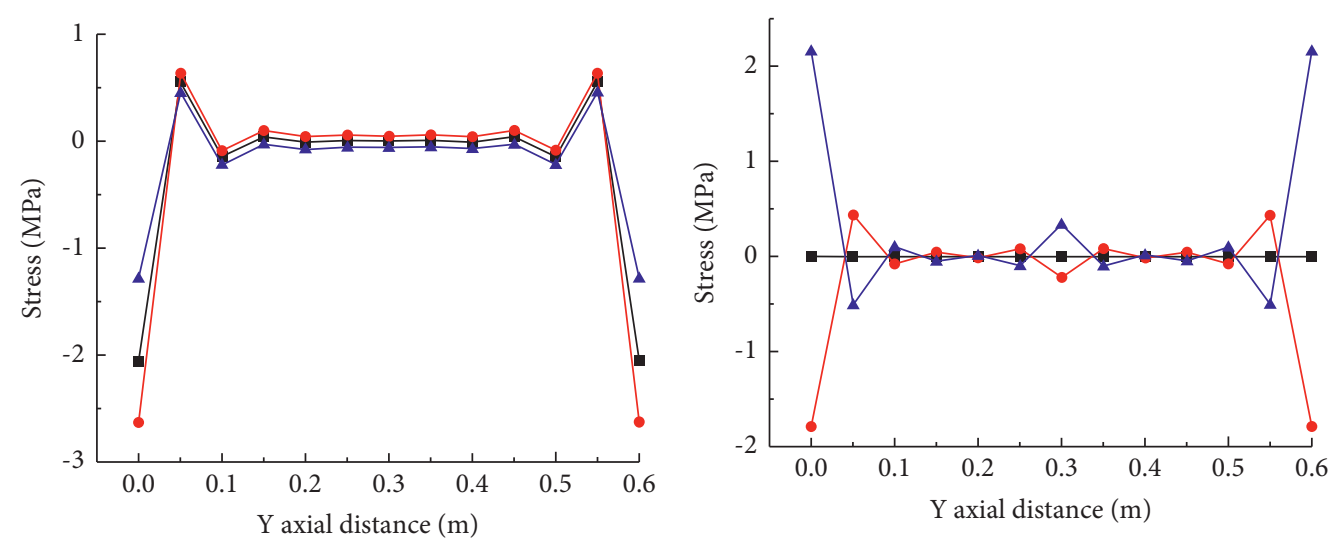

$$
\begin{aligned}
& \rightarrow \text { No Temperature } \\
& \longrightarrow 50^{\circ} \mathrm{C} \\
& \longleftarrow-20^{\circ} \mathrm{C}
\end{aligned}
$$

(a)

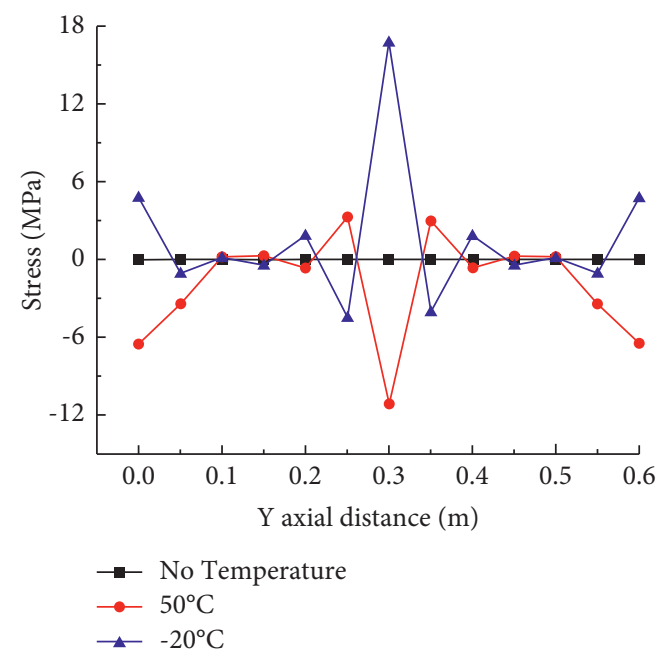

(c)

$$
\begin{aligned}
& \rightarrow \text { No Temperature } \\
& \rightarrow 50^{\circ} \mathrm{C} \\
& \longleftarrow-20^{\circ} \mathrm{C}
\end{aligned}
$$

(b)

\begin{tabular}{|c|c|c|c|c|c|c|c|}
\hline \multicolumn{4}{|c|}{ Strength under standard test conditions } & \multicolumn{4}{|c|}{ Strength under weather test conditions } \\
\hline $\begin{array}{l}\text { Curing } \\
\text { age }(d)\end{array}$ & $\begin{array}{c}\text { Flexural strength } \\
(\mathrm{MPa})\end{array}$ & $\begin{array}{c}\text { Compressive strength } \\
(\mathrm{MPa})\end{array}$ & $\begin{array}{l}\text { Folding } \\
\text { ratio }\end{array}$ & $\begin{array}{l}\text { Curing } \\
\text { period }\end{array}$ & $\begin{array}{c}\text { Flexural strength } \\
(\mathrm{MPa})\end{array}$ & $\begin{array}{c}\text { Compressive strength } \\
(\mathrm{MPa})\end{array}$ & Folding ratio \\
\hline 28 & 5.68 & 16.39 & 2.89 & - & - & - & - \\
\hline 33 & 7.17 & 18.66 & 2.60 & $28 \mathrm{~d}+20 \mathrm{H}-\mathrm{R}$ & 5.23 & 17.15 & 3.282 \\
\hline 38 & 7.06 & 18.88 & 2.67 & $28 \mathrm{~d}+40 \mathrm{H}-\mathrm{R}$ & 4.88 & 15.91 & 3.264 \\
\hline 43 & 7.38 & 18.97 & 2.57 & $28 \mathrm{~d}+60 \mathrm{H}-\mathrm{R}$ & 4.72 & 14.33 & 3.036 \\
\hline 48 & 7.6 & 19.51 & 2.60 & $28 \mathrm{~d}+80 \mathrm{H}-\mathrm{R}$ & 5.27 & 15.17 & 2.879 \\
\hline
\end{tabular}

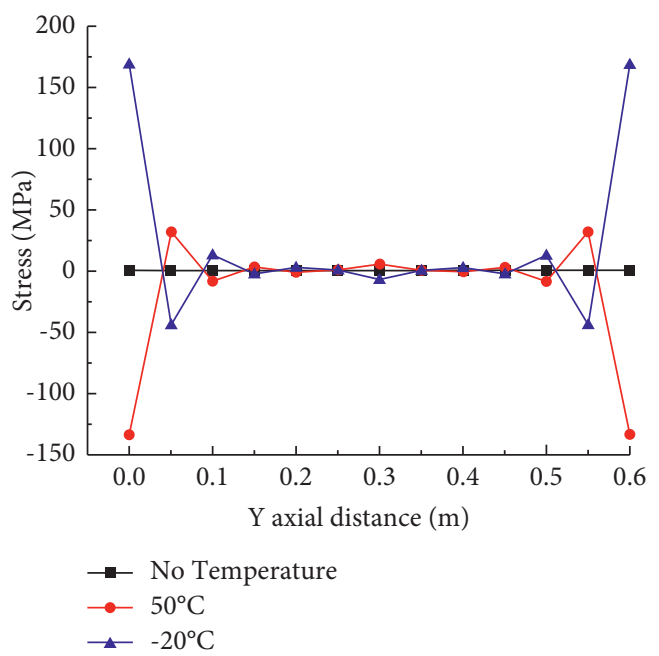

(d)

Figure 22: Comparison of normal bond stress of the semirigid finish layer. (a) Face brick. (b) Bonding layer. (c) Insulation layer. (d) Interface layer.

TABLE 6: Mechanical performance test of the polymer mortar.

TABLE 7: Bond strength of the polymer plastering mortar.

Strength under standard test conditions

Curing age (d) Bond strength with Bond strength with mortar block $(\mathrm{MPa})$ benzene board $(\mathrm{MPa})$

Curing period Flexural strength (MPa) Compressive strength (MPa)

\begin{tabular}{llllcl}
\hline 28 & 0.71 & 0.15 & - & - & 0.16 \\
33 & 0.80 & 0.16 & $28 \mathrm{~d}+20 \mathrm{H}-\mathrm{R}$ & 0.65 & 0.15 \\
38 & 1.02 & 0.20 & $28 \mathrm{~d}+40 \mathrm{H}-\mathrm{R}$ & 0.63 & 0.17 \\
43 & 1.04 & 0.19 & $28 \mathrm{~d}+60 \mathrm{H}-\mathrm{R}$ & 0.64 & 0.15 \\
48 & 1.05 & 0.15 & $28 \mathrm{~d}+80 \mathrm{H}-\mathrm{R}$ & 0.64 & \\
\hline
\end{tabular}




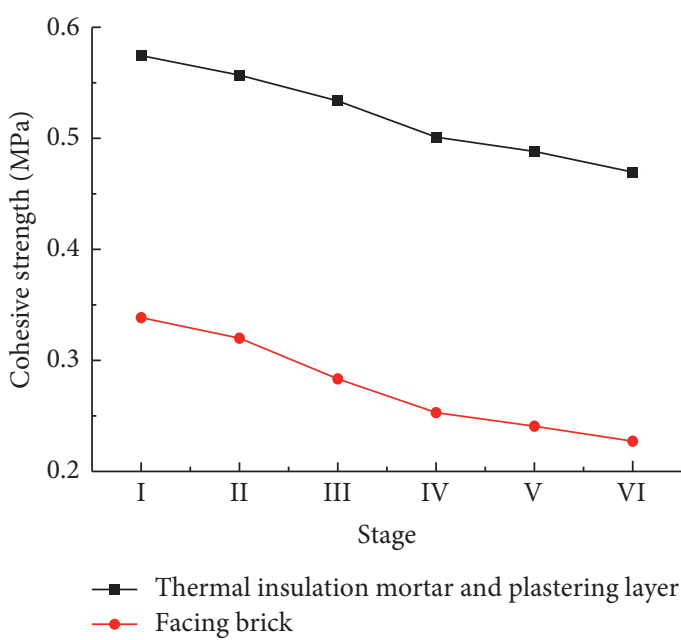

(a)

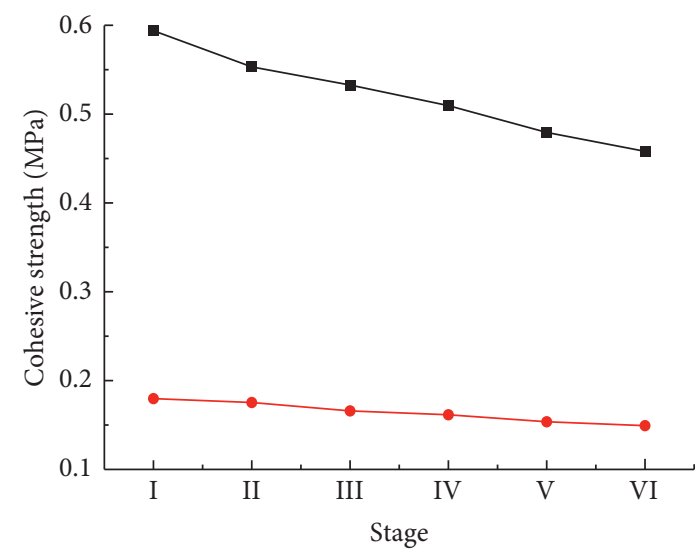

- Thermal insulation mortar and plastering layer

$\longrightarrow$ Facing brick

(b)

FIgURE 23: Bond strength curve. (a) Glazed bead thermal insulation mortar finish layer. (b) Modified polystyrene board finish layer.

TABle 8: Appearance and structure inspection index of the building finish layer.

\begin{tabular}{lcc}
\hline Component type & Test index & Weight \\
\hline External wall insulation panel components & Type of insulation board & 0.201 \\
& Dimensions of insulation board & 0.278 \\
& Surface cracks and defects & 0.255 \\
& Internal water seepage and absorption & 0.266 \\
Structural adhesive & Colloid layout size & 0.175 \\
& Appearance aging (discoloration) & 0.184 \\
& Colloid defect (blistering in colloid) & 0.173 \\
& The bond with the base wall has partial failure & 0.243 \\
Anchor bolt & bonding with the components of external insulation board has partial failure & 0.225 \\
\hline & Anchor bolt type & 0.185 \\
& Dimensions of the anchor bolt & 0.193 \\
Facing brick & Nurface corrosion of anchor bolt components & 0.185 \\
& Number of anchor bolts & 0.235 \\
\hline & Anchor bolt spacing & 0.202 \\
\hline
\end{tabular}

Table 9: Performance test index of building finish layer material.

\begin{tabular}{lcc}
\hline Component type & Test index & Weight \\
\hline External wall insulation panel & Tensile bond strength of the bonding layer and insulation layer & 0.245 \\
& Tensile bond strength between the insulation layer and brick layer & 0.223 \\
& Tensile strength of the insulation panel & 0.253 \\
& Water absorption of the insulation panel & 0.279 \\
\hline Structural adhesive & Tensile bond strength & 0.325 \\
& Shore hardness & 0.212 \\
& Maximum strength elongation & 0.201 \\
Anchor bolt & Failure area ratio of colloid bonding & 0.262 \\
\hline Facing brick & Tensile strength of the anchor bolt & 0.503 \\
\hline
\end{tabular}

$j=1,2, \ldots, k)$ of each evaluation index for $k$ individuals $(k \geq 30)$, the corresponding safety impact score is divided into group $p$ ( $p$ is generally $5-10$ ), the group distance is $h=\left(\max \left\{w_{i j}\right\}-\min \left\{w_{i j}\right\}\right) / p$, and calculate the frequency and frequency of the score value in each group; then, the corresponding weight of the evaluation index is 
TABLE 10: Test index of bearing capacity of the building finish layer.

\begin{tabular}{lcc}
\hline Component type & Test index & Weight \\
\hline & Wind pressure resistance test & 0.215 \\
& Impact resistance test & 0.203 \\
Overall decoration layer & Checking calculation of design bearing capacity & 0.221 \\
& Penetration resistance test & 0.183 \\
& Freeze thaw resistance test & 0.178 \\
\hline
\end{tabular}

TABLe 11: Safety classification of the finish layer.

Overall structure of the finish layer

I

II

III

IV
The bearing capacity is enough, which meets the requirements of the specification. The safety is slightly low, which meets the requirements of the specification.

The degradation of bearing capacity is large, and the safety does not meet the specification. Bearing capacity degradation is serious, safety is very low, neither meets the specification.

TABLE 12: Subjective evaluation index membership evaluation table hypothesis value.

\begin{tabular}{lcccc}
\hline I & $x_{11}$ & $x_{12}$ & 0 & \\
II & $x_{21}$ & $x_{22}$ & $x_{23}$ & 0 \\
III & 0 & $x_{32}$ & $x_{33}$ & $x_{34}$ \\
IV & 0 & 0 & $x_{43}$ & $x_{44}$ \\
\hline
\end{tabular}

$w_{i}^{\prime}=\sum_{k=1}^{p} \min \left\{w_{i j}\right\}+k h / 2 w_{k}$. The required bottom index weight $w_{i}$ can be obtained by normalization.

4.4. Membership Degree and Qualitative Index. The building finish layer system is evaluated in the form of an evaluation set, and the safety evaluation of the building finish layer is directly affected by the accuracy of the basic indicators. This article proposes a corresponding index system for different types of building finish layers, gives a level division interval of basic parameters, and determines the degree of membership.

In order to meet the fuzzy comprehensive evaluation combining quantitative and qualitative indicators, the quantification of the safety qualitative indicators of the building finish layer has been studied. There are four levels of subjective evaluation indicators, namely, I, II, III, and IV. The subjective evaluation index membership degree matrix is quantified in Table 12.

The hypothesis still needs to satisfy the following relations: For the subjective evaluation index $u_{i j}$, if the evaluation results of all components are $i$ level, $(i=1,2,3,4)$, it can be obtained that the index $u_{i j}$ of the component subunits are all $i$ level. The results are as follows:

$$
\begin{cases}x_{11}+2 x_{12}+<1.5, & x_{11}+x_{12}=1 \\ 1.5 \leq x_{21}+2 x_{22}+3 x_{23}<2.5, & x_{21}+x_{22}+3 x_{23}=1 \\ 2.5 \leq 2 x_{32}+3 x_{33}+4 x_{34}<3.5, & x_{32}+x_{33}+x_{34}=1 \\ 3.5 \leq 3 x_{43}+4 x_{44}, & x_{43}+x_{44}=1\end{cases}
$$

For situations that do not contain three or four-level components, the second secondary components are less than $30 \%$. Then, the subunit level of the component is the first level. For the situations where the fourth-level components are not included and the third-level components are less than $20 \%$, the subunit level of the component is the second level. For the case with four-level components, if the fourthlevel component is less than $10 \%$, it is a third-level component, and if it is greater than $10 \%$, it is a fourth-level component. The first-level evaluation rules are as follows:

$$
\left\{\begin{array}{l}
{\left[\begin{array}{ll}
0.7 & 0.3
\end{array}\right] \cdot\left[\begin{array}{llll}
x_{11} & x_{12} & 0 & 0 \\
x_{21} & x_{22} & x_{23} & 0
\end{array}\right]=\left[\begin{array}{llll}
a_{1} & a_{2} & a_{3} & a_{4}
\end{array}\right]} \\
\frac{a_{1}+2 a_{2}+3 a_{3}+4 a_{4}}{a_{1}+a_{2}+a_{3}+a_{4}}<1.5 \text { and close to } 1.5
\end{array}\right.
$$

According to the same judgment rules, similar inequality relations can be obtained at the second, third, and fourth levels. This article combines all the above inequality relations. Through trial calculations, a set of solutions given in Table 13 can be obtained. The membership level used for subjective evaluation index is given in Table 13 .

To sum up, the structural characteristics of the building finish layer are analyzed, and three relevant detection indexes, such as appearance and structure, material performance, and bearing capacity, of the building finish layer are determined. The comprehensive evaluation levels of the safety performance of the finish layer are divided, and the corresponding fuzzy evaluation methods are proposed for different structural levels and index systems. Use the method of questionnaire and frequency statistics to determine the weight and membership degree of the relevant detection index of the building decoration layer and determine the quantitative index and qualitative index. 
TABLE 13: Subjective evaluation index membership evaluation table.

\begin{tabular}{lcccc}
\hline I & 0.82 & 0.18 & 0 & 0 \\
II & 0.08 & 0.54 & 0.38 & 0 \\
III & 0 & 0.08 & 0.48 & 0.44 \\
IV & 0 & 0 & 0.08 & 0.92 \\
\hline
\end{tabular}

\section{Conclusions}

(1) The anchoring strength of the anchor bolt is positively correlated with the anchoring depth of the anchor bolt. The diameter of the influence of a single anchor bolt can reach $70 \mathrm{~mm}$, which is seven times the diameter of the anchor bolt. The maximum principal stress is $0.54 \mathrm{MPa}$, and the maximum bonding stress is $0.32 \mathrm{MPa}$. In addition, the simulation results are in good agreement with the results of anchor bolt pull-out tests.

(2) For the safety performance of the building finish layer, the temperature load has a significant effect. The coupling conditions of temperature-free stress field and temperature load are compared and analyzed. The results show that the temperature load not only increases the stress of the building finish layer but also affects its stress distribution. For low temperature environments, the influence of temperature load is more significant. It is consistent with the phenomenon that the building finish layer is more susceptible to damage in winter.

(3) Based on actual engineering and related literature, the influence of the heat-humidity cycle on the safety performance of the building finish layer is obtained. As the number of heat-moisture cycles increases, the plastic deformation of the material increases and the bond strength decreases to damage. At the same time, the heat-cold cycle damages the building finish layer more than the heat-humidity cycle.

(4) According to the appearance and structure, material performance, and bearing capacity, the weight relationship and membership relationship of the influencing factors of the finish layer are determined. The calculation formulas of the relevant quantitative and qualitative indexes are summarized, and the evaluation method for the finish layer is established.

\section{Data Availability}

The data used to support the findings of this study are included within the article.

\section{Conflicts of Interest}

The authors declare that they have no conflicts of interest.

\section{Acknowledgments}

This work was supported by the National Key Research and Development Plan of China (2017YFC0806100).

\section{References}

[1] Energy Consumption Statistics Committee of China Building Energy Efficiency Association, "China building energy consumption research report," Architecture, vol. 2019, no. 2, pp. 26-31, 2018.

[2] Energy Research, Investigators at University of Tehran Discuss Findings in Energy Research (Evaluation of Energy Consumption during Production and Construction of concrete and Steel Frames of Residential Buildings), Energy Weekly News, 2016.

[3] JGJ 144-2019, Technical Standard for External Thermal Insulation on Walls, Chinese Standards, 2019.

[4] D. O. Zhang and Z. L. Wang, "Experimental study on fatigue performance of anchor bolt of external wall insulation system," Construction technology, vol. 49, no. 9, pp. 24-30, 2020.

[5] J. Hopper, R. John, T. T. Littlewood et al., "Assessing retrofitted external wall insulation using infrared thermography," Structural Survey, vol. 30, no. 3, 2012.

[6] Q. Liang, J. F Liu, J. Liu, and G. Xu, "Effect of external wall insulation on building energy consumption, applied mechanics and materials," Journal of Southwest Forestry University (Natural Science), vol. 39, no. 3, pp. 183-188, 2019.

[7] Y. W. Ding, H. Y. Fu, Z. Wang, and Y. Cao, "Research progress of insulation and thermal and hygrothermal performance of timber structure walls," Journal of Southwest Forestry University (Natural Science), vol. 39, no. 3, pp. 183188, 2019.

[8] L. Yang, F. Y. Kong, and W. Wang, "Numerical simulation for temperature effect of external thermal insulation system with XPS board," Journal of Shenyang University of Technology, vol. 36, no. 6, pp. 701-705, 2014.

[9] J. Chen, Technical measures'Study on Surface's Cracking and Shedding of XPS External Insulation System, Shenyang Jianzhu University, Shenyang, China, 2015.

[10] J. Luo, Experimental Study on Fire Risk of EPS Building External wall Insulation System, Kunming University of science and technology, Kunming, China, 2013.

[11] B. Srinivasaraonaik, L. P. Singh, S. Sinha, I. Tyagi, and A. Rawat, "Studies on the mechanical properties and thermal behavior of microencapsulated eutectic mixture in gypsum composite board for thermal regulation in the buildings," Journal of Building Engineering, vol. 31, 2020.

[12] E. Mihlayanlar, Ş. Dilmaç, and A. Güner, "Analysis of the effect of production process parameters and density of expanded polystyrene insulation boards on mechanical properties and thermal conductivity," Materials and Design, vol. 29, no. 2, pp. 344-352, 2007.

[13] D. F. Li, The Study of Shear Bond Strength of Thermal Insulation Layer in Exterior Insulation System, Liaoning University of Technology, Jinzhou, China, 2016.

[14] R. Zhang, Experimental Study on the Fatigue Performance of Anchor Bolts of External wall Insulation System, Shandong Jianzhu University, Jinan, China, 2020.

[15] L. Ni, "Comparison and selection of exterior wall thermal lnsulation technology in shanghai area and study on anchor 
bolts tensile test," Building and Construction, vol. 40, no. 6, pp. 910-912, 2018.

[16] G. R. Finken, S. P. Bjarløv, and R. H. Peuhkuri, "Effect of façade impregnation on feasibility of capillary active thermal internal insulation for a historic dormitory - a hygrothermal simulation study," Construction and Building Materials, vol. 113, pp. 202-214, 2016.

[17] N. F. Jensen, S. P. Bjarløv, C. Rode, and E. B. Møller, "Hygrothermal assessment of four insulation systems for interior retrofitting of solid masonry walls through calibrated numerical simulations," Building and Environment, vol. 180, 2020.

[18] J. Cheng, X. H. Xu, X. Y. Zhang et al., "Numerical simulation of the weathering performance of an exterior wall external insulation system under heating-cooling cycles," Journal of Engineering Science, vol. 40, no. 6, pp. 754-759, 2018.

[19] Industry standard of the people's Republic of China, Technical Specification for External wall External Insulation Engineering (JGJ144-2017), China Construction Industry Press, Beijing, China, 2017.

[20] Industrial standard of construction industry of the people's Republic of China, Anchors for Fixing of thermal Insulation Composite Systems (JG/T366-2012), China Standards Press, Beijing, China, 2012.

[21] Industry standard for construction industry of the people's Republic of China, Autoclaved Aerated concrete Blocks (GB 11968-2006), China Construction Industry Press, Beijing, China, 2006.

[22] J. F. Luo, Research on Moisture Permeability and Fire Prevention Performance of Building ExternalInsulation Structure, Nanjing University of Aeronautics and Astronautics, Nanjing, China, 2013.

[23] L. X. Sun, Research on the Long-Term Performance of Stone WoolETICS under Coupled Heat and Mass Transfer Impact, Xi'an University of architecture and technology, Xi'an, China, 2018.

[24] Y. C. Liu, Investigation on Comprehensive thermal and Humidityperformance of Exterior wall Based on Composite Hygroscopicand thermal Insulation Mortar, Hunan University, Changsha, China, 2019.

[25] D. Y. Xiang, The Study on Thin Plastering External thermal Insualation Composite Systems under Weather-Text, Beijing University of technology, Beijing, China, 2008.

[26] Y. T. Huo, Experimental Study on Weatherability of Thermal Insulation System with Thermal Insulation Mortar and Modified Polystyrene Board, Taiyuan University of technology, Taiyuan, China, 2016.

[27] Industry standard of the people's Republic of China, Specification for Construction and Acceptance of Tapestry brick Work for Exterior wall (Jgj126-2015), China Construction Industry Press, Beijing, China, 2015.

[28] National standard of the people's Republic of China, Unified Standard for Constructional Quality Acceptance of Building Engineering (GB 50300-2013), China Construction Industry Press, Beijing, China, 2013.

[29] T. T. Huang, Z. Xu, D. W. Zhang, G. R. Ni, and W. L. Jin, "Comprehensive assessment of the durability of concrete beam bridges based on fuzzy theory," Highway, vol. 64, no. 3, pp. 141-145, 2019. 